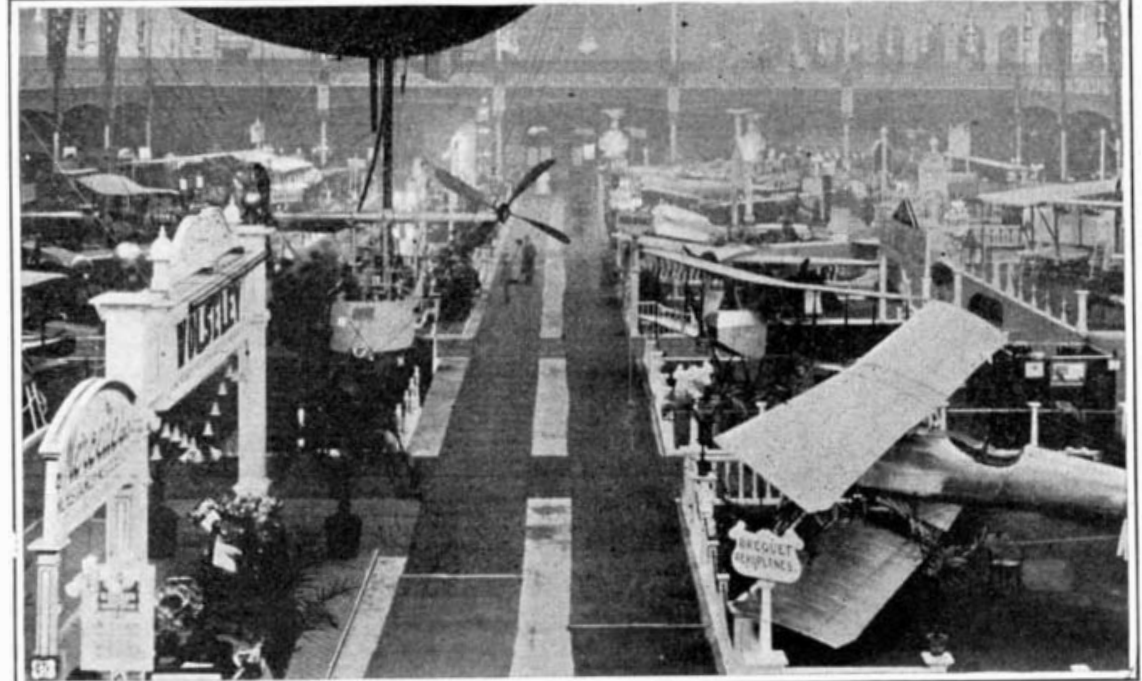

View of Exhibition Showing Government Dirigible "Delta" on Left and Breguet and Roe Biplanes and Nieuport Monoplane on Right.

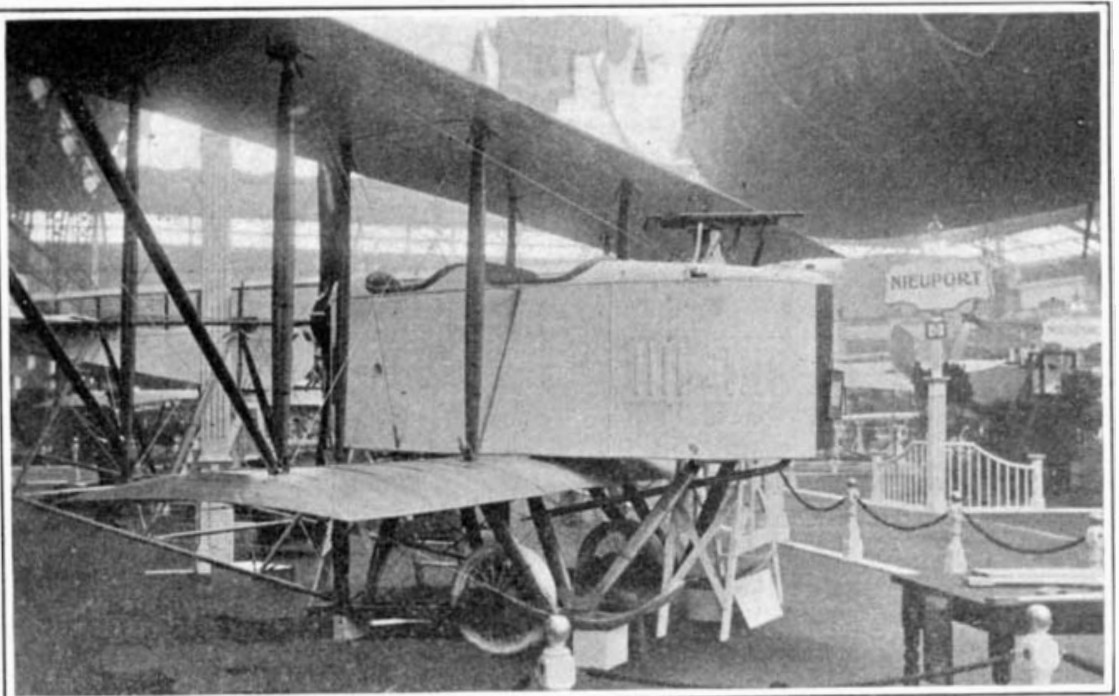

View Showing Porter Helicopter in Left Foreground and the War Office Biplan

" $\mathrm{BE}_{2}$ " in the Right. Next to Latter is Martin Handasyde Monoplane.

\title{
The Aeronautic Show at Olympia
}

\author{
Description of Some of the Principal Machines Exhibited
}

By Stanley Yale Beach

The Aeronautic Show at Olympia, in London, which took place last month, was the first big exhibition since the show in the Grand Palais, Paris, last October. Two thirds of the machines exhibited were of English design and manufacture, and in finish and workman-

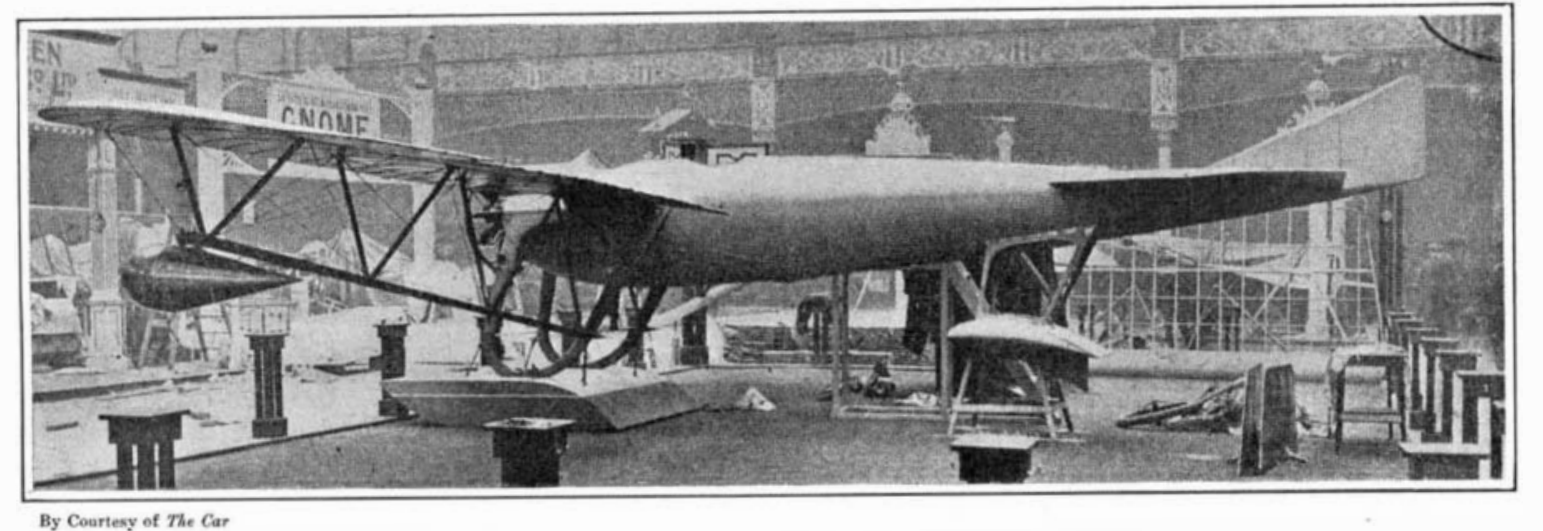

Side View of British-built Deperdussin Hydro-monoplane.

trussing below the wing and floats upon which body is mounte The entire

ship they are quite on a par with the aeroplanes turned out in France.

The machines that were exhibited were of two general classes, namrely, land machines and hydro-aeroplanes. Six out of the twenty-four aeroplanes shown were of the latter type. The land machines. were divided into military aeroplanes and aeroplanes for sport. As regards the former, there were several that were built not merely for scouting purposes, but rather for fighting in the air, since they were provided with rapid-fire guns capable of doing considerable damage, especially guns capable of doing considerable damage, especially to dirigibles. There were

monoplanes on exhibition.
Several of the photographs reproduced herewith give a general idea of the exhibition. As will be seen, the government dirigible "Delta" occupied a central position, while the War Office aeroplane " $\mathrm{BE}_{2}$ " can be seen on the right of one of the illustrations, at the top of this page. The huge Cody biplane, which has flown over 7,000 miles and which was the winner of the Military Competition last August, was also exhibited by the War Office. It has shown a speed of 72 miles per hour and a climbing ability of 300 feet per minute.

Two of our illustrations show the Breguet military biplane in the foreground, while still another picture shows a Caudron biplane in the right corner, with a Farman biplane behind it, and a Martin Handasyde Farman biplane behind it, and

Coming now to the war machines, the huge biplane fitted with a quick-firing gun, exhibited by GrahameWhite, was one of the most notable. This machine is shown in one of our illustrations. It was provided with a 90 horse-power Austro-Daimler motor, which was mounted at the front of the car, just back of the radiator. The motor was fitted with a muffler, making conversation possible between the pilot and passenger. A shaft running back from the motor was arranged to drive the propeller by means of sprockets and chain, the gear reduction being 14 to 23 . Arrangements were made for $1 / 2$-inch take-up on the chain. The propeller was mounted upon the upper member of a triangular fuselage, and so fitted that it can readily be removed desired. The Colt gun was mounted above the ront end of the car, with seats for the gunner and his helper just back of it. The gun had a range of a vertical plane. The pilot was placed back of the gunner, and controlled the machine by a vertical lever and foot tiller, as usual. Below the pilot's feet was a large gasoline tank having enough capacity for a 6-hour flight." The fuel was forced by the exhaust pressure from the engine to a small tank in front and above the level of the carbureter, so that the final feed was by gravity. A special gage was arranged to indicate

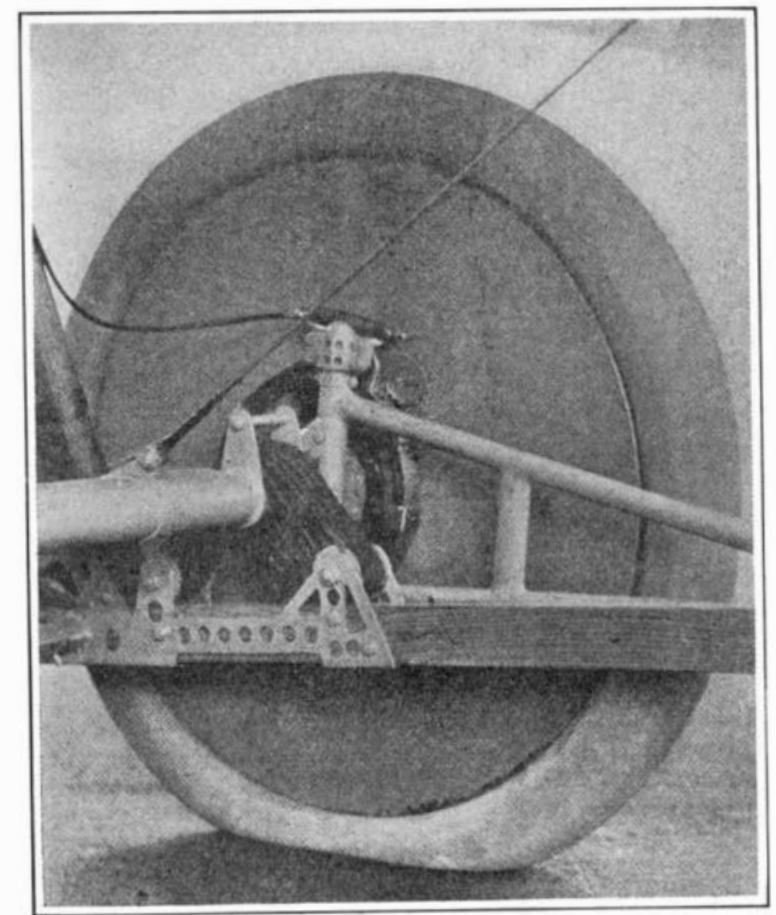

Detail of Bristol Biplane.

Note disk wheel fitted with band brake, and method of (rom axle by elastic cord. the amount of fuel in the service tank. The machine had wide skids made up of two pieces of wood connected together by cross-members and by metal at the front. Wheels having twin rims and tires were placed in the middle of each skid, the skid being supported from the wheel hub by means of leaf-springs and hangers. The chord of the surfaces was 6 feet, and the pread of the upper plane 42 feet as against 23 feet of the lower. The total supporting surface was 435 square feet. The planes were built with the same cross section as the Eiffel experimental plane "No. 8," They could be quickly detached and laid alongside the $71 / 2$-foot center section for towing over the road. The tail was made up of a single flat surface containing 50 square feet, while the elevator flaps has an area of 25 square feet, and the vertical rudder one of 23 square feet. The weight of this machine without passengers or fuel was 2,100 pounds. It was designed to carry 750 pounds useful load and is expected to make 50 to 70 miles an hour when fitted with a 120 horse-power engine

A second war biplane was the Vickers. This is a biplane with a Maxim gun which can be swung through 120 degrees in either a vertical or horizontal plane.

Of the two seats, the gunner occupies the forward one and can draw within reach a box with 1,500 rounds of ammunition. This box is mounted on wires and ordinarily rests at or near the center of gravity of the machine. It can be moved back and forth by the gunner with ease. The pilot sits immediately behind the gunner and the motor is placed back of the pilot, with the propeller mounted upon its cam shaft so that it therns at half the speed of the engine. This power, air-cooled motor with water-cooled heads, of the 8-cylinder, $\mathrm{V}$ type. The feature of this machine is the fitting of a duplicate control for the gunner in case any accident befalls the pilot. The body of the aeroplane is of steel tubing covered with sheet Duralumin. It has a stream line form. The machine is a staggered biplane, the upper plane being placed somewhat in advance of the lower. Strand steel cable is used for the guys in place of piano wire, the latter being used only in the body. The planes can be taken off quickly, leaving the center section of each no wider than the body. In the interior of the center section of the upper plane is a small gasoline tank from which fuel is fed by gravity to the carbureter. The gasoline is forced to this tank from the main tank in the body by pressure, the pipes for this purpose being concealed in the hollow spars. No oil tank is needed, as sufficient oil is carried in the base of the motor for a 6-hour flight. An improved military tractor biplane for scouting was the two-seater "Bristol." This machine had an over-all length of 28 feet, a spread of 37 feet, and a supporting surface of 440 square feet. Its weight empty, was 940 pounds and it will carry a useful load of 880 pounds. With a speed of 60 miles per hour, it has a radius of action of 120 miles, four hours' flight. It is fitted with a non-lifting tail consisting of the usual fixed surface and winged elevator. A balanced vertical rudder is located in front of the elevator, which is at the extreme end of the regular monoplane body. The chassis of this machine has several novel features. Four disk wheels are located at the four corners, one 


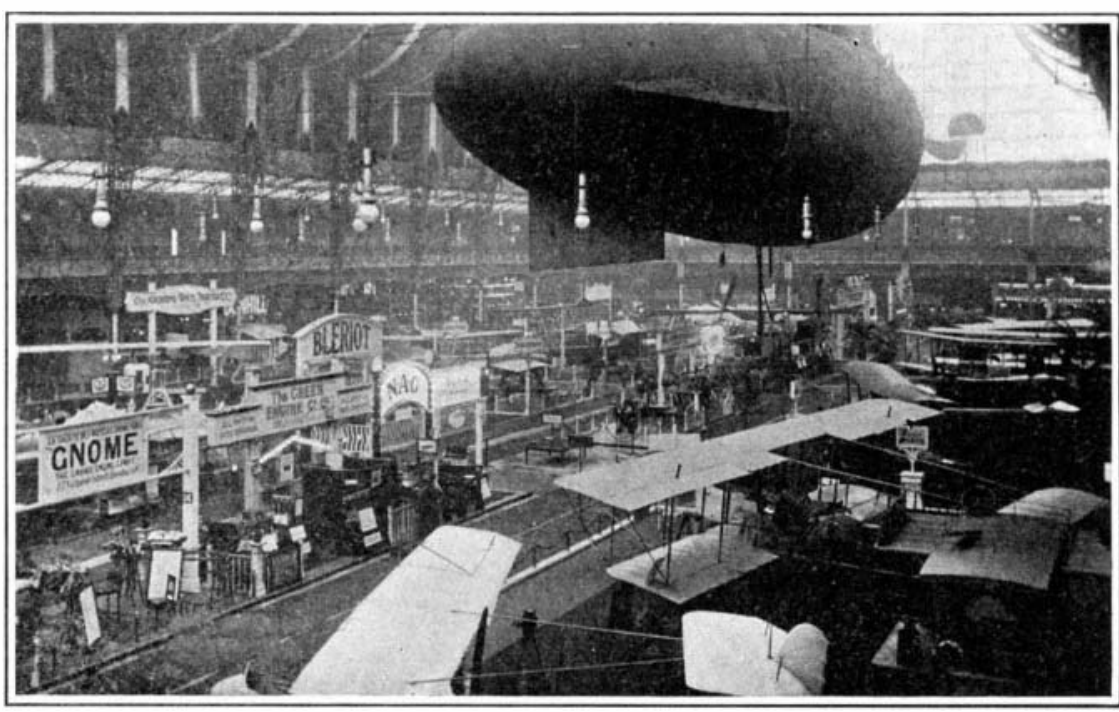

The Motor Stands are Seen on the Left, with the Caudron and Farman Biplanes in the Foreground on the Right.

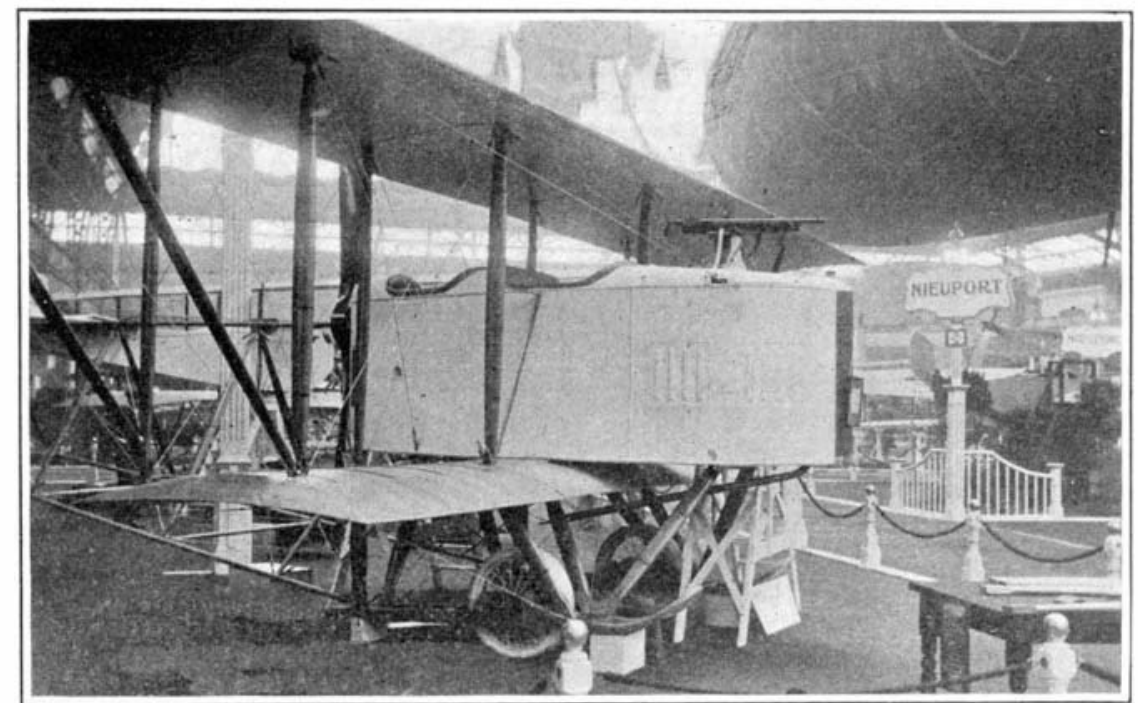

Grahame-White's New War Biplane, Showing Maxim Gun and Radiator in Front and Propeller at Rear of Body. at each corner of a rectangular frame to which the body is connected by four inclined struts. The rear wheels are the larger and carry most of the weight The rectangular frame is suspended from their axle by means of elastic cords in the manner shown in the detailed photograph reproduced on this page. Band brakes are fitted to each of these rear wheels for the purpose of making a quick stop as well as for steering when the machine is running slowly over the ground. By means of separate levers the brates can be applied individully for stering. The wheels to convert this machine into a hydro-aeroplane.

The chief novelty in construction was shown in the British-built Deperdussin hydro-monoplane, shown in one of our illustrations. This novelty consisted in dispensing with all the usual guys, and bracing the wings on their under side with strong triangular trusses of steel tubing. This method of wing bracing is said to be much stronger than the usual one with guys, the consequence being that a heavy landing will not deform the wings. Compression of the wing spars is greatly minimized, a very important point, and the time taken to assemble or dismantle is lessened. The total weigh of the steel tubing for trussing the wings is but 35 pounds, so this system is no heavier than the usual in that only the part back of the rear spar is flexible. in that only the part back of the rear spar is flexible This warping portion of each wing is extremely flexible and should not deteriorate with use. The wings are wider at the tips than at the shoulder. They are covered with a special fabric having threads arranged in bunches and running at right angles to each other, forming squares. The perforation of one or more of these squares by bullets would not harm the wing. The body of this machine is built in lengthwise halves instead of being machine is built in lengthwise halves instead of being
in a single piece as in the French monocoque. The torin a single piece as in the French monocoque. The tor-
pedo shape is identical, however. Each half is constructed by laying narrow strips of tulip wood over a form. The strips are in three layers, those of the first two layers running at right angles to each other. Two coverings of strong fabric are applied to the outside, so that a stiff integral shell is formed that requires no internal bracing. The tail surface is slightly cambered so as to lift about 80 pounds. A small cambered float is provided beneath the tail. The single wide float in front is flat bottomed. It consists of an ash frame covered with three-ply wood and canvas. Both

floats support the body by means of oval frames. In the case of the land machine, the axle of the two disk wheels is attached to the large oval frame by elastics. The passenger sits in front of the pilot and has a good

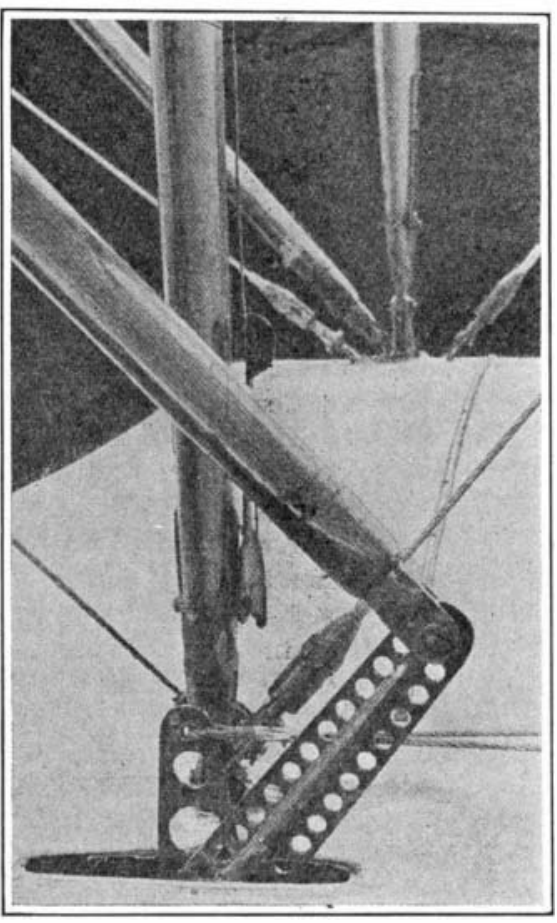
New Method of Warping Wings on Grahame-White's
Biplane. The warping is accomplished by means of levers, thus dis-
pensing with cables and pulleys.

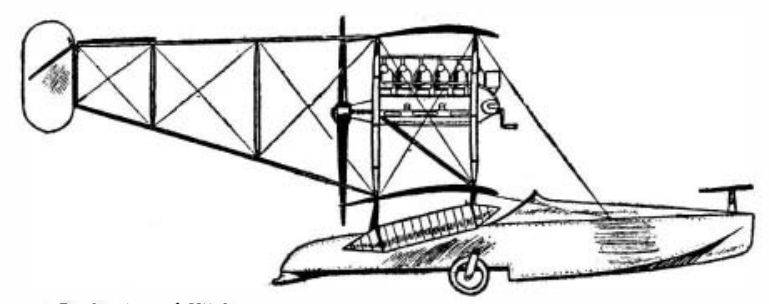

Side View of Sopwith Flying Boat. A biplane mounted upon a single-step hydroplane hull. view downward, as the wings are cut away for the purpose. The main fuel tank is flush with the floor between the two seats. The gasoline is fed by a small automatic pump to the service tank above and just behind the motor. The passenger has in front of him gauge glasses showing whether or not the fuel is flowing. Should these break, the gasoline can be shut off and danger from fire avoided. The dimensions, etc., of this hydro-monoplane are: Length, 26 feet; spread, 43 feet; area, 330 square feet; weight, empty, 1,160 pounds; useful load, 730 pounds; speed, 63 miles per hour; motor, 100 horse-power circular Anzani.

The chief attempt at improving the hydro-aeroplane seen at the show was the flying boat of T. O. M. Sopwith. Mr. Sopwith has simply mounted a biplane upon a 21-foot hydroplane having a single step and a beam of 4 feet, sufficient to seat the pilot and passenger side by side. This boat was built of 'cedar by Saunders after his ingenious method of sewing two layers of wood together by means of copper wire and attaching them in like manner to the skeleton of the hull. These layers are very thin and make the whole boat weigh only 180 pounds. The step is placed 12 feet from the bow and has a depth of between 3 and 4 inches. Two wheels are arranged on an axle in such a way that they can be raised out of action when the boat is operating on the water, and dropped down into place when a landing is to be made upon terra firma.

The biplane mounted upon this hull has a spread of 11 feet with a chord of $51 / 2$ feet. Its total area is 422 square feet. The length over all of the machine is 32 feet, and its weight empty 1,200 pounds. A 90 horse-power, 6-cylinder Austro-Daimler motor drives this machine at a speed of 65 miles an hour, and when carrying two persons and a load of fuel, the weight carried per square foot is 4 pounds. The struts and main spars are made of hollow built-up sections using ash and spruce for the center and outside respectively. The ribs are made of a very elastic wood and it is possible to twist them to an angle of over 90 degrees without having them lose their shape. The tail of the machine, rectangular in shape and containing 22 square feet of surface, is made up largely of steel tubing, as are also the tips and trailing edge of the main planes. The result in the latter case is that the camber is maintained at all times and good efficiency is obtained. A front elevator is mounted on top of the bow of the boat and acts in conjunction with the one at the rear.

\section{Continuous Rail for Chicago Street Traction}

\section{The Story of a Rush Order}

Tie Man from London appeared before the Board of Supervising Engineers Chicago Traction on the 28th of July, 1911, and offered to lay before the end of the year ten miles of continuous rail, which had been tried out in England and France.

"Impossible," said the Board. "We have contracted for all the work we intend to do this year; and we have no such mileage to build." "Good," said the Man from London, "let's discuss details,"

On the 31st of July, on his way home he telegraphed from Pittsburgh, asking if the Board would do six miles. Promptly the answer came back, "No, two miles is all we can do." By the time he reached New York, a compromise had been made; and four miles had been agreed to.

On the 10th of $\Lambda$ ugust he was back in Chicago; and on the 17th a draft agreement, between the Board and the English Company he represented, was in his pocket as he made his way to the "Twentieth Century"

Hurriedly reading through the "whereases" and the "now, therefores," he found that the Board wished him to guarantee the delivery of a machine from England by the 20th of October; to guarantee delivery of one thousand tons of rails from the rolling mills by that time, and apparently to guarantee that the weather in Chicago after the 20th of October would be suitable for the carrying out of the contract. " $\Lambda \mathrm{nd}$, furthermore," he was to guarantee that the inventor would come over from England to do the work within a prescribed and limited time.

From Cleveland he telegraphed his acceptance of the terms of the contract; and the following morning in New York called upon the president of one of our great steel frms, to whom he had previously presented a letter of introduction.

"I have an unsigned contract in my pocket," said the Man from London, "which requires one thousand tons of steel rail of an entirely new design to be manufactured and delivered in the city of Chicago by the 20th day of October. I have been told by two or three rail manufacturers that this is impossible; and I have therefore, come to you to have the thing done."

"Have you seen the manager," said the president "Yes," said the Man from London. "He says that com mercially it is impossible, but physically it is within the range of possibility."

"Good," said the president. "We are in business to do the commercially impossible; and it is our policy to encourage any advance in the art connected with our business." 